\title{
Differences in Thermoregulatory Ability Between Slick-Haired and Wild-Type Lactating Holstein Cows in Response to Acute Heat Stress
}

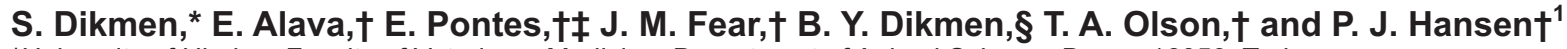 \\ *University of Uludag, Faculty of Veterinary Medicine, Department of Animal Science, Bursa, 16059, Turkey \\ †University of Florida, Department of Animal Sciences, Gainesville 32611-0910 \\ łUniversidade de São Paulo, Faculdade de Medicina Veterinária e Zootecnia, São Paulo, Brazil \\ §University of Uludag, Keles Vocational School, Keles, Bursa, 16740, Turkey
}

\section{ABSTRACT}

Animals inheriting the slick hair gene have a short, sleek, and sometimes glossy coat. The objective of the present study was to determine whether slick-haired Holstein cows regulate body temperature more effectively than wild-type Holstein cows when exposed to an acute increase in heat stress. Lactating slick cows $(n=10)$ and wild-type cows $(n=10)$ were placed for 10 $\mathrm{h}$ in an indoor environment with a solid roof, fans, and evaporative cooling or in an outdoor environment with shade cloth and no fans or evaporative cooling. Cows were exposed to both environments in a single reversal design. Vaginal temperature, respiration rate, surface temperature, and sweating rate were measured at $1200,1500,1800$, and $2100 \mathrm{~h}$ (replicate 1) or 1200 and $1500 \mathrm{~h}$ (replicate 2), and blood samples were collected for plasma cortisol concentration. Cows in the outdoor environment had higher vaginal and surface temperatures, respiration rates, and sweating rates than cows in the indoor environment. In both environments, slick-haired cows had lower vaginal temperatures (indoor: 39.0 vs. $39.4^{\circ} \mathrm{C}$; outdoor 39.6 vs. $40.2^{\circ} \mathrm{C}$; $\mathrm{SEM}=$ 0.07 ) and respiration rate (indoor: 67 vs. 79 breaths/ min; outdoor 97 vs. 107 breaths/min; $\mathrm{SEM}=5.5$ ) than wild-type cows and greater sweating rates in unclipped areas of skin (indoor: $57 \mathrm{vs} .43 \mathrm{~g} \cdot \mathrm{h}^{-1} / \mathrm{m}^{2}$; outdoor $82 \mathrm{vs}$. $61 \mathrm{~g} \cdot \mathrm{h}^{-1} / \mathrm{m}^{2}$; SEM = 8). Clipping the hair at the site of sweating measurement eliminated the difference between slick-haired and wild-type cows. Results indicate that slick-haired Holstein cows can regulate body temperature more effectively than wild-type cows during heat stress. One reason slick-haired animals are better able to regulate body temperature is increased sweating rate.

Key words: heat stress, Holstein, slick hair gene, sweating and respiration rate

Received February 3, 2008

Accepted May 21, 2008.

${ }^{1}$ Corresponding author: Hansen@animal.ufl.edu

\section{INTRODUCTION}

Genetic variance for heat tolerance exists in dairy cattle and improvement can be expected through selection (Ravagnolo and Misztal, 2000). Few specific genes have been identified that control heat tolerance. One such gene is the slick hair gene (slick hair), which controls hair length. Originally described in Senepol cattle, the gene was subsequently identified in Carora cattle (Olson et al., 2003) and introduced into Holsteins by crossbreeding. The gene has been mapped to chromosome 20 (Mariasegaram et al., 2007). Animals with the dominant allele have a very short, sleek, and sometimes glossy coat. Cattle with slick hair coats experience lower body temperatures in heat stress conditions. The superior thermoregulatory ability associated with the slick phenotype is apparently the result of increased convective and conductive heat loss and decreased absorption of solar radiation. Milk yield for Carora $\times$ Holstein cows in Venezuela was higher for animals with slick hair than for their contemporaries with wild-type hair (Olson et al., 2003).

Although differences in thermoregulatory ability between slick and wild-type cows were observed under heat stress conditions (Olson et al., 2003), no study has been performed to compare body temperature regulation during experimentally imposed heat stress. The aim of the present study was to determine 1) whether slick-haired Holstein cows regulate body temperature more effectively than wild-type Holstein cows when exposed to an acute increase in heat stress and 2) whether this difference is caused by differences in sensible or evaporative heat loss.

\section{MATERIALS AND METHODS}

\section{Animals and Treatments}

The experiment was conducted with slick $(n=10)$ and wild-type $(\mathrm{n}=10)$ lactating Holstein cows at the Dairy Research Unit in Hague, FL. Slick-haired cows were out of Holstein cows and were sired by 3 differ- 
ent 3/4 Holstein and 1/4 Senepol bulls heterozygous for Slick. Of the wild-type cows, 2 were siblings of the slickhaired cows used in the study and 8 were unrelated. Within hair type, cows were paired according to their parity, stage of lactation, and milk yield and randomly assigned within pair to 1 of 2 groups (sequence 1 and sequence 2). Differences between slick and wild-type cows in age, DIM, and milk yield ( $2.6 \pm 0.6$ vs. $2.7 \pm 0.5$ yr; $135.3 \pm 17.4$ vs. $138.5 \pm 16.9 \mathrm{~d}$, and $27.3 \pm 1.4$ vs. $28.2 \pm 1.6 \mathrm{~kg}$, respectively) at the start of the experiment were not significant $(P>0.05)$.

When not used for the experiment, cows were maintained in a free-stall barn containing fans and sprinklers. The experiment was conducted on August 20, 2007 (replicate 1) and August 24, 2007 (replicate 2). The experimental design involved a single reversal arrangement of environmental treatments. Cows in sequence 1 were housed in the indoor environment for replicate 1 and the outside environment for replicate 2 , and cows in sequence 2 were housed in the outside environment for replicate 1 and the indoor environment for replicate 2 .

On each experimental day, cows assigned to the indoor environment were moved at $1100 \mathrm{~h}$ to a concrete block building with a ceiling height of $3 \mathrm{~m}$ and in a 15 $\times 6 \mathrm{~m}$ pen with a concrete floor. The pen was ventilated by a pair of 0.91-m diameter fans located at each end of the long sides of the pen. In addition, cows were soaked thoroughly with water via a hose at 15-min intervals from 1100 to $2100 \mathrm{~h}$. Cows remained in the pen until $2100 \mathrm{~h}$. Cows in the outdoor environment were housed from 1100 to $2100 \mathrm{~h}$ in a $10 \times 8 \mathrm{~m}$ pen located outside. The pen had a concrete floor and was covered by shade cloth (73\% reduction in solar radiation; Donovan Enterprises, Stuart, FL) suspended 3 m overhead. Sprinklers were not present, and cows were not manually wetted. During the experiment, feed and water were available ad libitum for both groups. Cows were milked twice daily between 0800 to $1000 \mathrm{~h}$ and 2100 to $2300 \mathrm{~h}$.

The experiment for replicate 2 was terminated prematurely because a rainstorm occurring at $1630 \mathrm{~h}$ resulted in cooling of cows in the outside environment. Accordingly, data from cows were collected from 1200 to $1500 \mathrm{~h}$ only.

\section{Environmental Measurements}

On each experimental day, black globe temperature, dry bulb temperature, relative humidity $(\mathbf{R H})$, and dew point temperature were recorded every $15 \mathrm{~min}$ in each environment at a height of $2 \mathrm{~m}$. Dry bulb temperature, $\mathrm{RH}$, and dew point temperature were measured using a HOBO-U12 data logger (Onset Company, Bourne, MA). The temperature-humidity index (THI) was calculated according to the equation reported by Ravagnolo et al. (2000):

$$
\begin{aligned}
\mathrm{THI}=(1.8 \times \mathrm{T}+32)-[(0.55-0.0055 \times \mathrm{RH}) \\
\times(1.8 \times \mathrm{T}-26)],
\end{aligned}
$$

where $\mathrm{T}=$ dry bulb temperature $\left({ }^{\circ} \mathrm{C}\right)$ and $\mathrm{RH}=$ relative humidity (\%).

\section{Physiological Measurements}

Vaginal temperature was measured at 15 -min intervals from 1100 to $2100 \mathrm{~h}$ using a HOBO water temperature Pro V2 data logger (Onset Company, Bourne, MA) attached to a blank (i.e., without progesterone) controlled internal drug releasing device (CIDR, Pfizer Animal Health, New York, NY) that was inserted into the vagina. Respiration rate, surface temperature, and sweating rate were measured at 1200, 1500, 1800, and $2100 \mathrm{~h}$. Respiration rate was measured by counting flank movements for a 1-min period. Surface temperature was measured at unclipped black areas on the thigh, loin, and shoulder of the right and left sides of the cow using an infrared thermometer (Sixth Sense LT300 Infrared Thermometer, TTI Instruments, Williston, VT) held $20 \mathrm{~cm}$ from the surface. For replicate 1, sweating rate was estimated using a Vapometer (Delfin Technologies Ltd., Kuopio, Finland) on an unclipped area of the right shoulder. For replicate 2, sweating rate was measured on 2 areas of the right shoulder: an unclipped area and a closely clipped and brushed area. Hair was clipped using an Oster PowerPro hair clipper with Opti-Block blade kit (Oster Professional Products, McMinnville, TN).

Coccygeal blood samples were collected via venipuncture at 1200, 1500, 1800, and $2100 \mathrm{~h}$ using heparinized Vacutainer tubes for determination of cortisol concentrations. Samples were placed on ice until centrifuged at $1,000 \times \mathrm{g}$ for $30 \mathrm{~min}$ at $4^{\circ} \mathrm{C}$. Plasma was harvested and stored at $-20^{\circ} \mathrm{C}$ until analysis. Cortisol concentrations were measured using solid-phase RIA (Coat-ACount cortisol kit, Diagnostic Products, Los Angeles, CA). The intraassay coefficient of variation was $14.9 \%$.

\section{Statistical Analysis}

Data were analyzed using the PROC GLM procedure of SAS (v. 9.1.3; SAS Institute Inc., Cary, NC). Three analyses were performed. The first analysis was for data collected for replicate 1 . The mathematical model included main effects of environment, hair type (slick and wild-type hair), cow nested within hair type and environment, time of day, and all interactions. The second analysis considered data collected on both replicates from the period between 1200 and 1500 h (i.e., 
before rain in replicate 2). The model included environment (i.e., the day $\times$ sequence interaction), hair type (slick and wild-type hair), cow nested within hair type, time of day, and all interactions. The third analysis was for sweating rate for replicate 2 (1200 and 1500 h). The model included effects environment, hair type (slick and wild-type hair), cow nested within hair type and environment, time of day, clipping (yes or no), and all interactions. For all analyses, cow was considered a random effect and other main effects were considered fixed. Tests of significance were calculated using expected mean squares. A probability of $P<0.05$ was considered significant.

\section{RESULTS}

\section{Environmental Conditions}

The environmental conditions in each treatment are shown in Figure 1. For replicate 1, the outdoor environment was characterized by higher dry bulb temperatures (from 1100 to $1845 \mathrm{~h}$ ) and THI (from 1100 to 1830 $\mathrm{h}$ except at 1415, 1515, and $1600 \mathrm{~h}$ ) than the indoor environment. The THI remained greater than 80 in both groups for the duration of experiment. Relative humidity was lower in the outdoor environment from 1100 to $1900 \mathrm{~h}$. In replicate 2 before $1630 \mathrm{~h}$, when a rainstorm occurred, dry bulb temperature and THI were higher and $\mathrm{RH}$ lower for the outdoor environment than the indoor environment Following the rainstorm at $\sim 1630 \mathrm{~h}$, the dry bulb temperature in the outdoor environment became less than that in the indoor environment and the RH became greater. The THI became lower for the outdoor environment than the indoor environment, but was lower in both environments than before the rain.

\section{Replicate 1}

Data were analyzed separately for replicate 1 because physiological measurements were collected throughout the experimental period, whereas the occurrence of rain in replicate 2 compromised effects of treatment on measurements collected after $1500 \mathrm{~h}$.

Results for vaginal temperature are in Figure 2A and for surface temperature in Figure 2B. Vaginal temperature was higher for cows in the outdoor environment than for cows in the indoor environment $(P<0.001)$. Slick-haired Holsteins had lower vaginal temperatures than wild-type Holsteins in both environments $(P<$ 0.05 ), and there was no hair type $\times$ environment interaction. Vaginal temperatures in wild-type Holsteins were generally above $39^{\circ} \mathrm{C}$ in both environments. There were fluctuations in vaginal temperature in cows in the indoor environment that may reflect an increase in temperature coincident with blood sampling. Surface temperature was greater for cows in the outdoor environment $(P<0.001)$, but there was no significant effect of hair type or interactions with hair type. There was an effect of time $(P<0.001)$ and environment $\times$ time interaction $(P<0.001)$, which largely reflected that surface temperature at the beginning of the experiment (1200 h) was very high in cows in the outdoor environment and then decreased rapidly thereafter.

Data on evaporative cooling are in Figure 3. Respiration rates were higher for cows in the outdoor environment than for cows in the indoor environment $(P<0.001)$ and were lower for slick-haired cows than for wild-type cows $(P<0.05$; Figure 3A). There were no interactions between hair type and other effects. Sweating rate was higher for cows in the outdoor environment $(P<0.001$; Figure 3B). Sweating rate decreased toward the end of the day (time, $P<0.001$ ), and the differences between environments decreased during this time (environment $\times$ time interaction, $P<0.01$ ). There was a tendency for sweating rate to be greater for slick-haired cows than wild-type cows (hair type, $P=0.075$; hair type $\times$ time interaction, $P=0.08)$. Cortisol concentrations were not affected by main effects or interactions (Figure 3C).

\section{Combined Analysis of Replicates 1 and 2}

An analysis of the complete data set was performed for the period from 1200 to $1500 \mathrm{~h}$ (before occurrence of rain in replicate 2). There were no interactions between hair type and time, and data are presented as pooled across time. As displayed in Figure 4A, vaginal temperature was higher for the outdoor environment $(P<0.001)$ and lower for slick-haired cows than wildtype cows $(P<0.01)$. Surface temperature was higher for the outdoor environment $(P<0.001)$, but there was no effect of hair type (Figure 4B). Respiration rate was higher for the outdoor environment $(P<0.001)$ and lower for slick-haired cows than wild-type cows $(P<$ 0.03; Figure 5A). Sweating rate was higher for the outdoor environment $(P<0.02)$ and higher for slick-haired cows than wild-type cows $(P<0.01$; Figure $5 \mathrm{~B})$. There were no hair type $\times$ environment interactions affecting vaginal temperature, surface temperature, respiration rate, or sweating rate. Cortisol concentrations were not affected by environment or the hair type $\times$ environment interaction, although there was a tendency $(P<0.08)$ for higher concentrations for slick-haired cows than wild-type cows (Figure 5C).

\section{Sweating Rate in Replicate 2}

In replicate 2 , sweating rate was measured in both clipped and unclipped regions of the skin to determine 


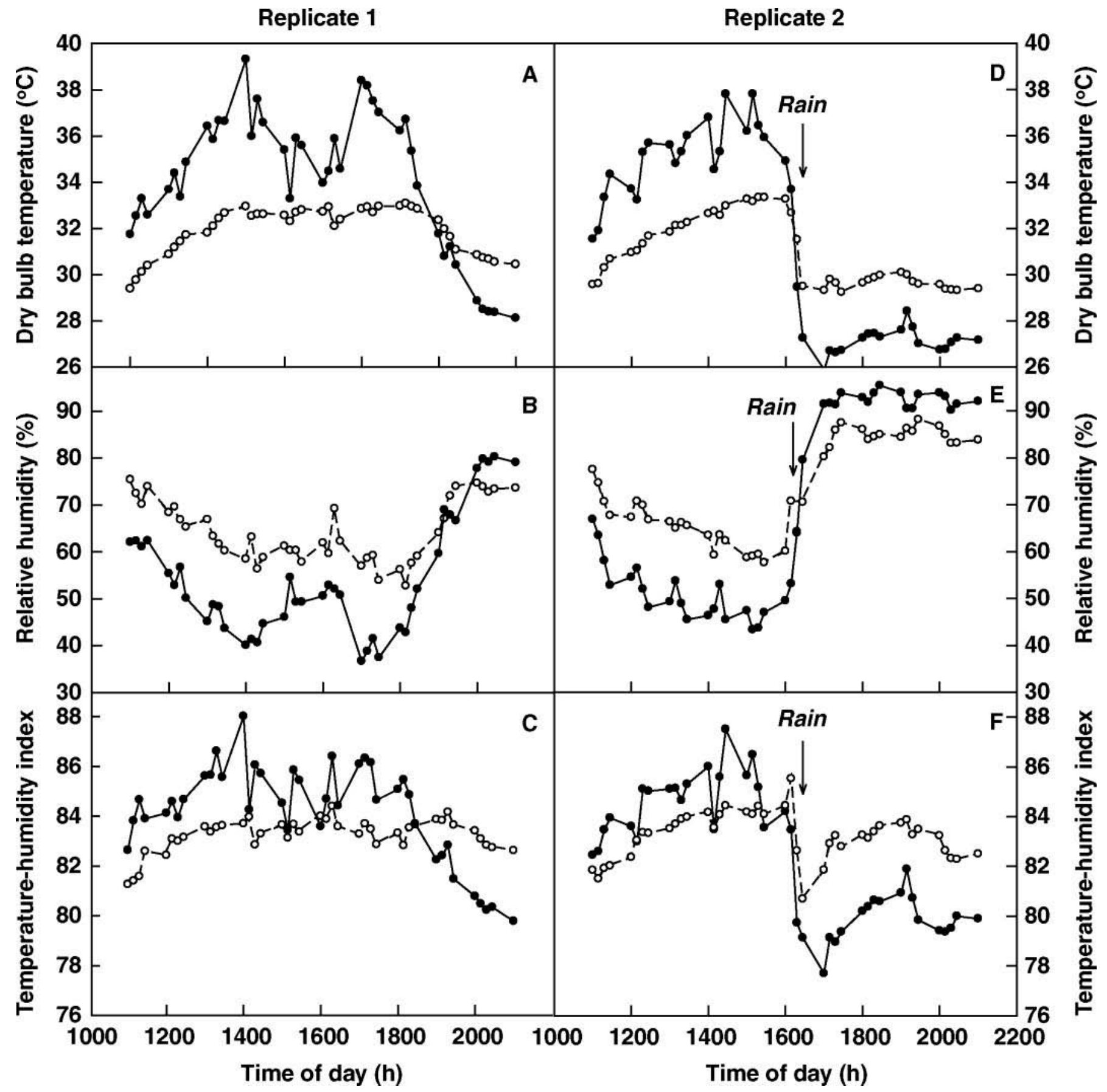

Figure 1. Environmental variables for replicates 1 and 2. Solid circles with solid lines represent data for the outdoor environment and open circles with dashed lines represent data for the indoor environment.

if the differences in sweating rate between hair types were a direct effect of hair length (Figure 6). Sweating rate was greater for the clipped area than for the unclipped area $(P<0.001)$ and greater in the outdoor environment $(P<0.02)$. There were clipping $\times$ hair type $(P<0.01)$ and clipping $\times$ environment $(P<0.01)$ interactions. Sweating rate was greater for slick-haired cows than for wild-type cows in unclipped areas, but lesser for slick-haired cows than for wild-type cows in clipped areas. Also, the difference between indoor and outdoor environments was greater for the clipped area than the unclipped area. 


\section{DISCUSSION}

Results presented here confirm earlier findings (Olson et al., 2003) that slick-haired cattle were better able to regulate body temperature than wild-type contemporaries. The increased thermal resistance of the slick-haired animals was likely due in part to increased sweating rate.

Differences in thermal regulation between slickhaired and wild-type cows were observed in the indoor and outdoor environments. Cows in both environments were subjected to heat stress. In the indoor environment, the THI ranged between 81.4 and 84.4, values that are considered above the threshold for heat stress (West, 2003). Moreover, vaginal temperature of control cows with wild-type hair in the indoor environment were generally above $39^{\circ} \mathrm{C}$, whereas lactating cows in the thermoneutral zone have temperatures lower than $39^{\circ} \mathrm{C}$ (Meyer et al., 1995; Trout et al., 1998; Wilson et al., 1998). Cows in the outdoor environment were subjected to more severe heat stress as indicated by increases in THI, vaginal and surface temperature, respiration rate, and sweating rate. That slick-haired cows were better able to regulate their body temperature in both environments indicates the potential for the slick hair gene to improve thermal resistance of lactating cows in a variety of hot environments.

Cows were not evaluated for body temperature regulation in an environment free of heat stress, and it cannot be ruled out that some or all of the difference in vaginal temperatures between slick-haired and wildtype cattle represent differential body temperature regulation independent of heat stress. In one study in cool weather, slick-haired beef cattle had lower rectal temperatures than wild-type cattle (Olson et al., 2003).

The physiological basis for improved body temperature regulation in slick-haired cows must involve lower metabolic rate, increased sensible or evaporative heat loss, more efficient transfer of heat to the animal surface (determined largely by blood flow and anatomical characteristics of the respiratory tract), or a combination of these adaptations. Milk yield was similar between slick and wild-type cows, and it is unlikely that there were major differences in metabolic rate between groups. Slick-haired cows have very short hair coats and should therefore have increased rate of heat loss via convection and conduction (Berman, 2004). In addition, it is possible that such hair coats are more effective at reflecting solar radiation than hair coats normally present on Holsteins. The present study shows that evaporative heat loss via sweating was greater in slick-haired cows than wild-type cows. Moreover, the basis for the increased sweating rate is the short hair

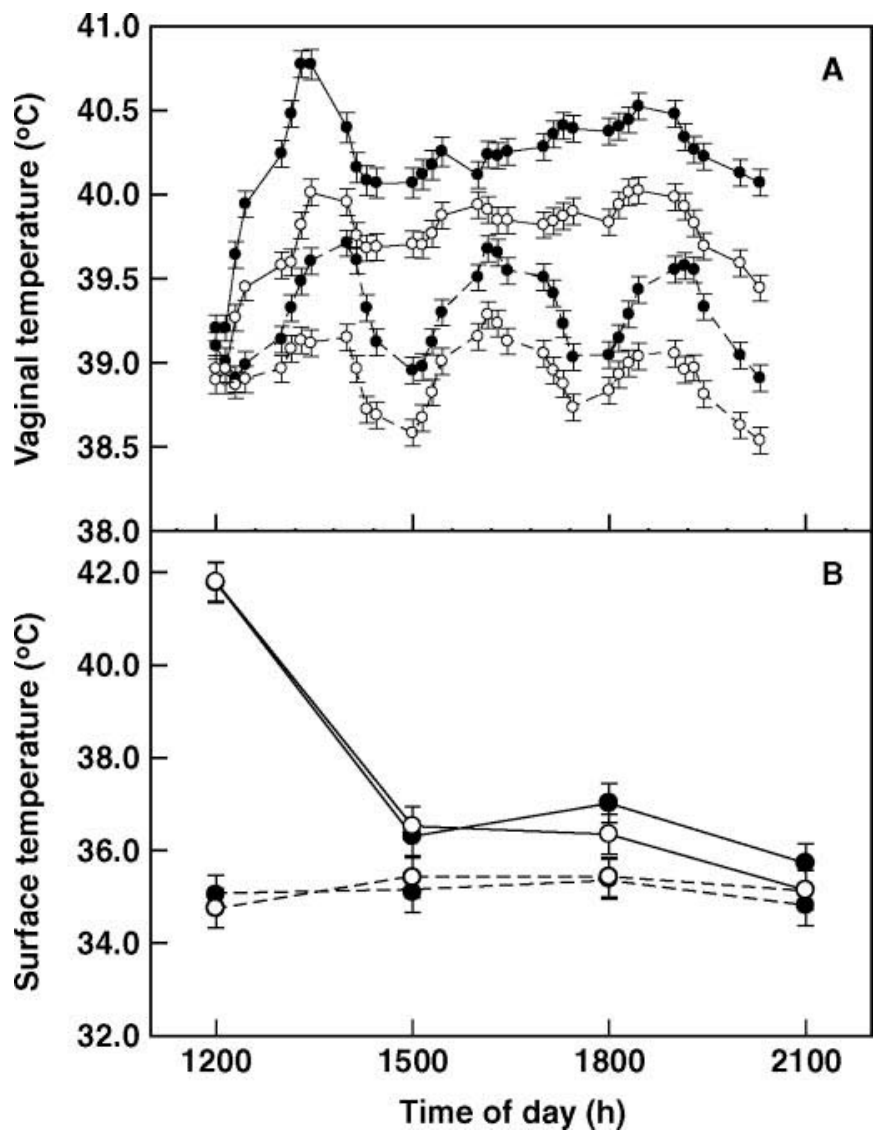

Figure 2. Vaginal (A) and surface (B) temperatures of slick (open circles) and wild-type Holsteins (closed circles) in indoor (dashed lines) and outdoor environments (solid lines) for replicate 1. Data are least squares means \pm SEM. Vaginal temperature was affected by hair type $(P=0.05)$, environment $(P<0.001)$, time of day $(P<0.001)$, and environment $\times$ time of day interaction $(P<0.001)$. Surface temperature was affected by environment $(P<0.001)$, time of day $(P<$ $0.001)$, and environment $\times$ time of day interaction $(P<0.001)$.

coat length and the concomitant reduction in humid air trapped at the skin surface because differences in sweating rate between slick-haired and wild-type cows were eliminated by clipping the hair coat. The superior sweating rate of slick-haired cows may be very important in hot environments because $85 \%$ of heat loss from the skin at air temperatures greater than $30^{\circ} \mathrm{C}$ is via evaporation (Maia et al., 2005). The reduction in respiration rate of slick-haired cows as compared with wild-type cows can be ascribed to the increased rate of cutaneous heat loss for slick-haired animals.

There is indirect evidence that delivery of heat from the body core to the skin is greater for slick-haired cows than for wild-type cows. If heat delivery to the skin was similar for slick-haired and wild-type cows, one would expect slick-haired cows to have lower surface temperatures because of greater sensible and evaporative heat loss. There was no difference in surface temperature 


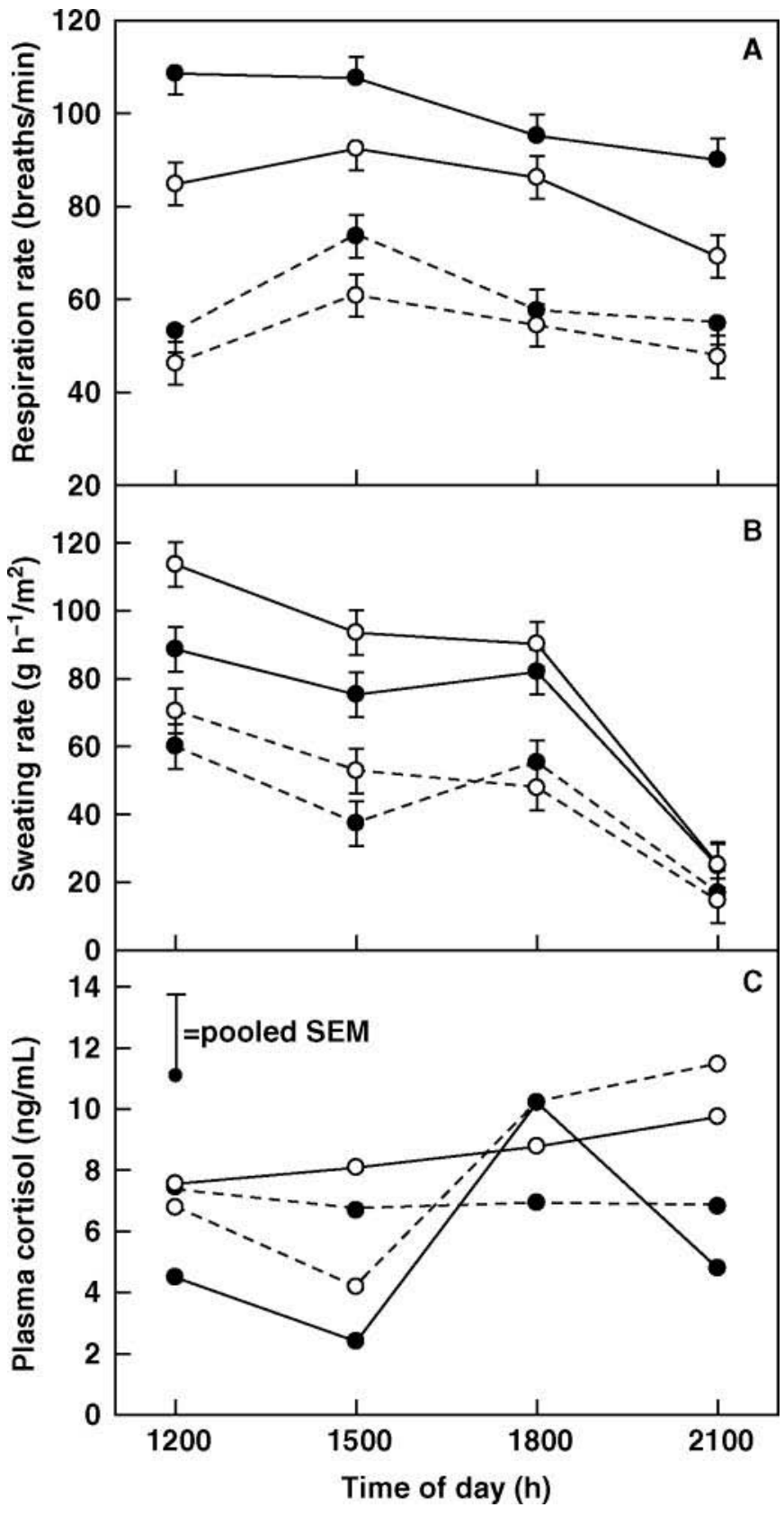

Figure 3. Respiration rate (A), sweating rate (B) and plasma cortisol concentrations (C) of slick (open circles) and wild-type Holsteins (closed circles) in indoor (dashed lines) and outdoor environments (solid lines) for replicate 1. Data are least squares means \pm SEM. Respiration rate was affected by hair type $(P<0.05)$, environment $(P$ $<0.001)$, time of day $(P<0.001)$, and environment $\times$ time of day interactions $(P<0.05)$. Sweating rate tended to be affected by hair type $(P=0.07)$ and hair type $\times$ time interaction $(P=0.08)$ and was affected by environment $(P<0.001)$, time of day $(P<0.001)$, and environment $\times$ time of day interaction $(P<0.01)$. Cortisol was not affected by any main effect or interaction.

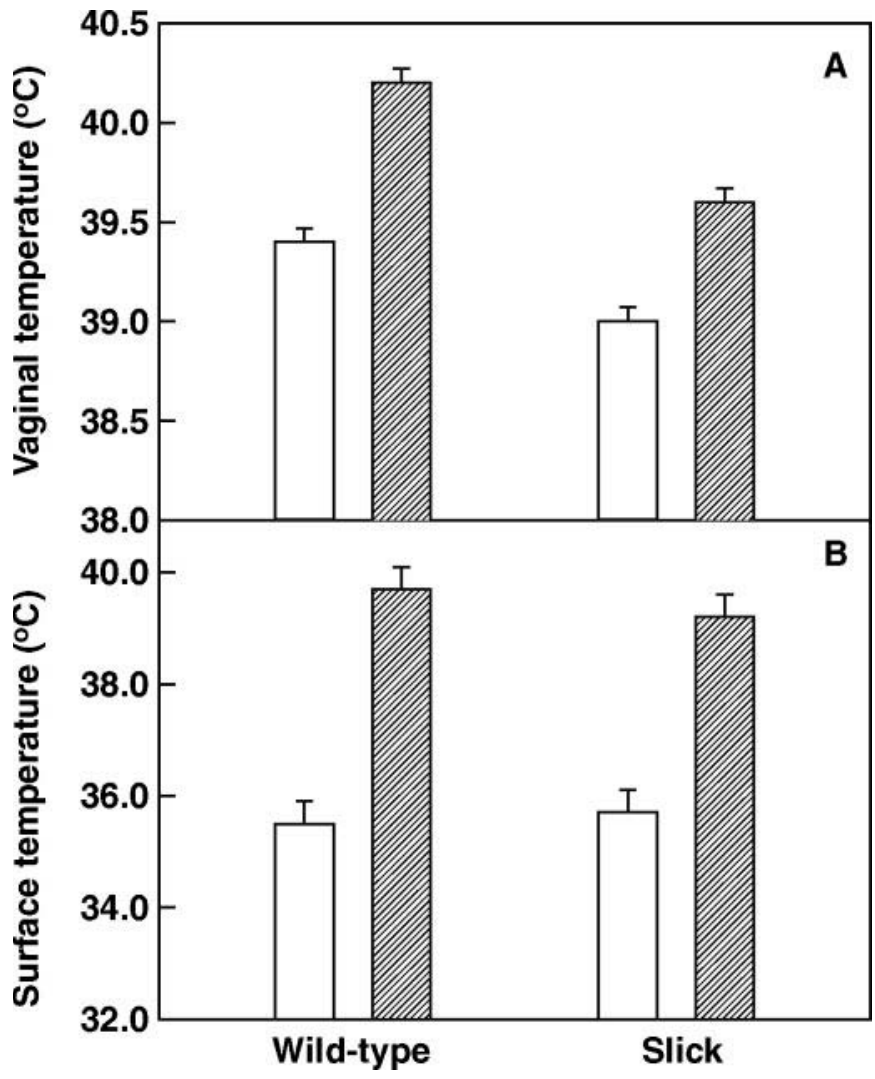

Figure 4. Vaginal (A) and surface (B) temperatures for replicates 1 and 2 from 1200 to $1500 \mathrm{~h}$ as affected by hair type and environment (indoor, open bars; outdoor, hatched bars). Data are least squares means \pm SEM. Vaginal temperature was affected by hair type $(P<$ $0.01)$ and environment $(P<0.001)$, and surface temperature was affected by environment $(P<0.001)$.

between slick and wild-type cows. This suggests that delivery of heat to the skin is enhanced in slick cows.

Cortisol concentrations did not differ between environments or increase during the day. There are conflicting data in the literature regarding actions of heat stress on circulating cortisol concentrations in lactating cows. One report indicated that cortisol concentrations increase after $4 \mathrm{~h}$ of exposure to heat stress (Christison and Johnson, 1972). Chronic exposure to heat stress over several days or longer increased (Wise et al., 1988a; Elvinger et al., 1992), decreased (Christison and Johnson, 1972; Correa-Calderon et al., 2004), or had no effect (Wise et al., 1988b; Johnson et al., 1991) on circulating cortisol concentrations. Perhaps the high variability associated with concentrations of this hormone, as well as psychological factors affecting cortisol secretion (Herskin et al., 2007; Curley et al., 2008), obscured effects of heat stress.

The increased milk yield seen in slick-haired dairy cows in Venezuela (Olson et al., 2003) probably reflected the greater capacity of slick-haired cows for cutane- 


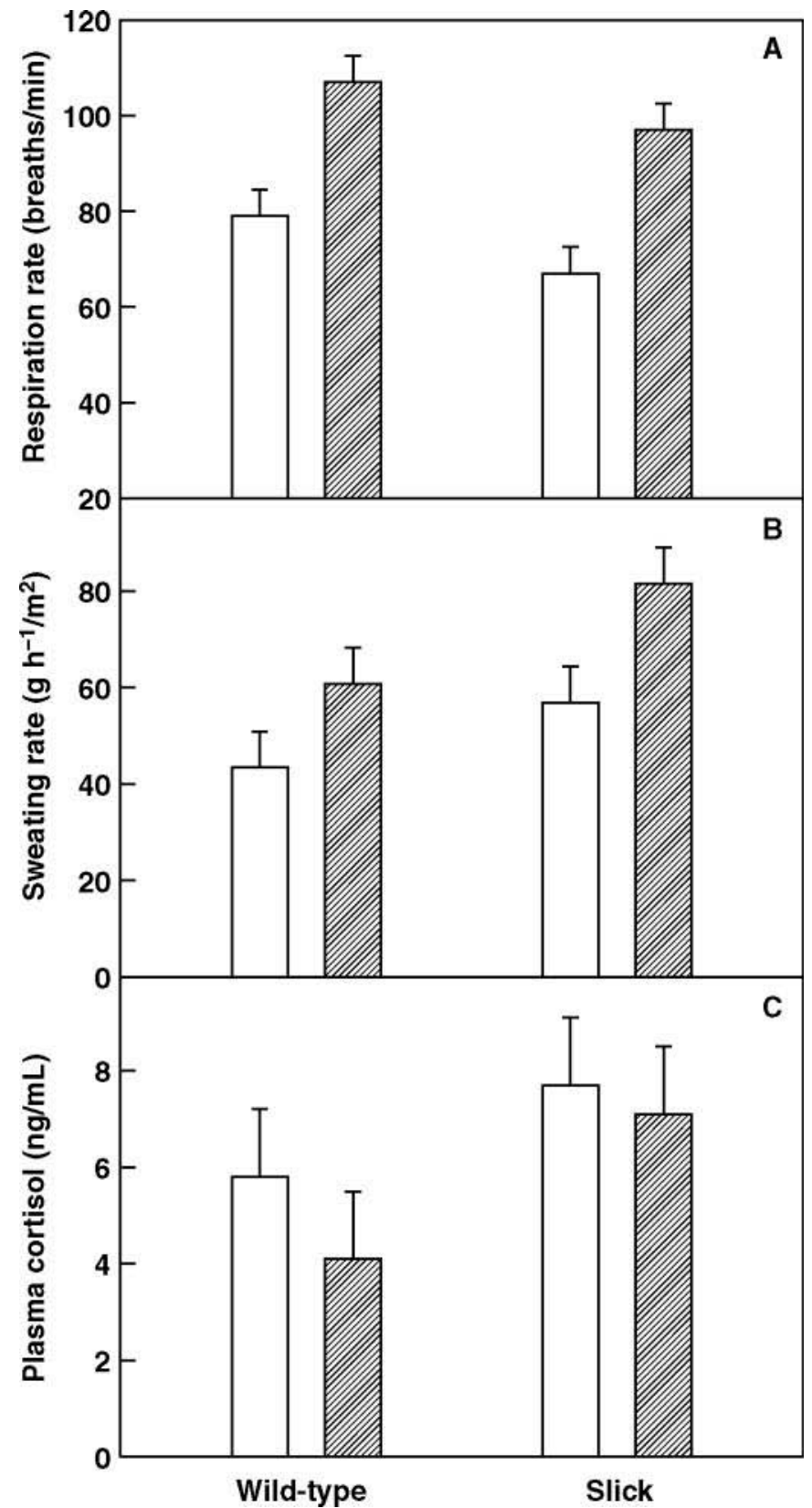

Figure 5. Respiration rate (A), sweating rate (B), and plasma cortisol concentrations (C) for replicates 1 and 2 from 1200 to $1500 \mathrm{~h}$ as affected by hair type and environment (indoor, open bars; outdoor, hatched bars). Data are least squares means \pm SEM. Respiration rate was affected by hair type $(P<0.03)$ and environment $(P<0.001)$. Sweating rate was affected by hair type $(P<0.01)$ and environment $(P<0.02)$. There was a tendency for cortisol concentrations to be affected by hair type $(P<0.08)$.

ous heat loss. Incorporation of the slick hair gene into dairy cows may result in improved capacity for body temperature regulation and enhanced productivity in hot climates.

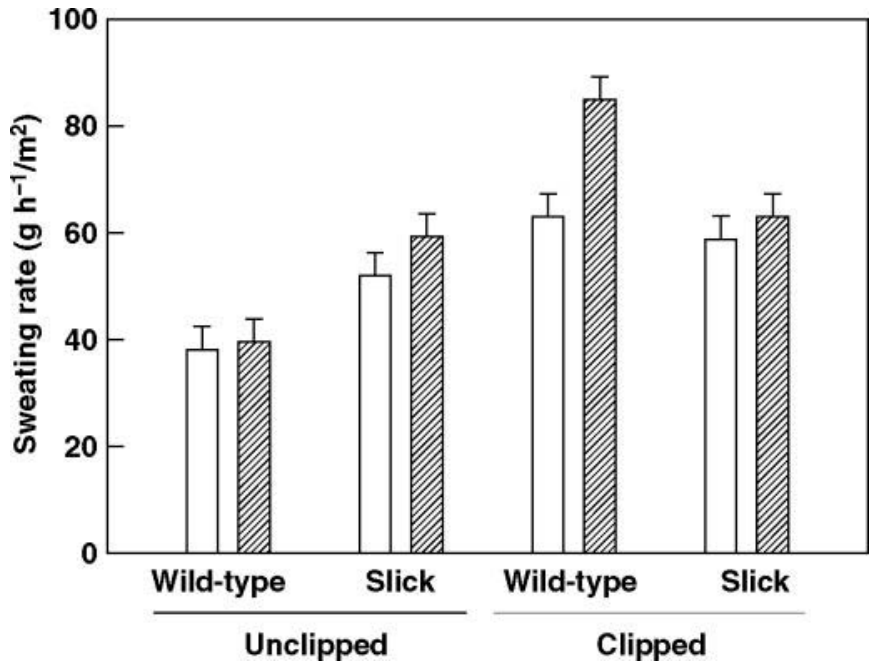

Figure 6. Effect of clipping hair on differences in sweating rate between slick-haired and wild-type cows. Data were collected for replicate 2 from 1200 to $1500 \mathrm{~h}$. Shown are least squares means \pm SEM from unclipped areas (open bars) and clipped areas (hatched bars). Sweating rate was affected by environment $(P<0.02)$, clipping $(P<$ $0.001)$, clipping $\times$ hair type $(P<0.01)$, and clipping $\times$ environment $(P$ $<0.01$ ) interactions.

\section{ACKNOWLEDGMENTS}

Serdal Dikmen was supported by a grant from TUBITAK-BIDEB Ankara, Turkey. Additional support was provided by USDA Grant no. 2001-52101-11318 from the Initiative for Future Agricultural and Food Systems Program. The authors thank Maria Beatriz Padua, Jim Moss, Aline Bonilla, Leydson Martins, and Barbara Loureiro (University of Florida) for assistance in data collection.

\section{REFERENCES}

Berman, A. 2004. Tissue and external insulation estimates and their effects on prediction of energy requirements and of heat stress. J. Dairy Sci. 87:1400-1412.

Christison, G. I., and H. D. Johnson. 1972. Cortisol turnover in heatstressed cows. J. Anim. Sci. 35:1005-1010.

Correa-Calderon, A., D. Armstrong, D. Ray, S. DeNise, M. Enns, and C. Howison. 2004. Thermoregulatory responses of Holstein and Brown Swiss heat-stressed dairy cows to two different cooling systems. Int. J. Biometeorol. 48:142-148.

Curley, K. O. Jr., D. A. Neuendorff, A. W. Lewis, J. J. Cleere, T. H. Welsh Jr., and R. D. Randel. 2008. Functional characteristics of the bovine hypothalamic-pituitary-adrenal axis vary with temperament. Horm. Behav. 53:20-27.

Elvinger, F., R. P. Natzke, and P. J. Hansen. 1992. Interactions of heat stress and bovine somatotropin affecting physiology and immunology of lactating cows. J. Dairy Sci. 75:449-462.

Herskin, M. S., L. Munksgaard, and J. B. Andersen. 2007. Effects of social isolation and restraint on adrenocortical responses and hypoalgesia in loose-housed dairy cows. J. Anim. Sci. 85:240247.

Johnson, H. D., R. Li, W. Manalu, K. J. Spencer-Johnson, B. A. Becker, R. J. Collier, and C. A. Baile. 1991. Effects of somatotropin on 
milk yield and physiological responses during summer farm and hot laboratory conditions. J. Dairy Sci. 74:1250-1262.

Maia, A. S. C., R. G. daSilva, and C. M. B. Loureiro. 2005. Sensible and latent heat loss from the body surface of Holstein cows in a tropical environment. Int. J. Biometeorol. 50:17-22.

Mariasegaram, M., C. C. Chase Jr., J. X. Chaparro, T. A. Olson, R. A. Brenneman, and R. P. Niedz. 2007. The slick hair coat locus maps to chromosome 20 in Senepol-derived cattle. Anim. Genet. 38:54-59.

Meyer, M. D., P. J. Hansen, W. W. Thatcher, M. Drost, and R. M. Roberts. 1995. Effect of bovine interferon- $\tau$ on body temperature and plasma progesterone concentrations in cyclic dairy cows. J. Dairy Sci. 78:1470-1476.

Olson, T. A., C. Lucena, C. C. Chase Jr., and A. C. Hammond. 2003. Evidence of a major gene influencing hair length and heat tolerance in Bos taurus cattle. J. Anim. Sci. 81:80-90.

Ravagnolo, O., and I. Misztal. 2000. Genetic component of heat stress in dairy cattle, parameter estimation. J. Dairy Sci. 83:21262130.
Ravagnolo, O., I. Misztal, and G. Hoogenboom. 2000. Genetic component of heat stress in dairy cattle, development of heat index function. J. Dairy Sci. 83:2120-2125.

Trout, J. P., L. R. McDowell, and P. J. Hansen. 1998. Characteristics of the estrous cycle and antioxidant status of lactating Holstein cows exposed to heat stress. J. Dairy Sci. 81:1244-1250.

West, J. W. 2003. Effects of heat-stress on production in dairy cattle. J. Dairy Sci. 86:2131-2144.

Wilson, S. J., R. S. Marion, J. N. Spain, D. E. Spiers, D. H. Keisler, and M. C. Lucy. 1998. Effects of controlled heat stress on ovarian function of dairy cattle. 1. Lactating cows. J. Dairy Sci. 81:21242131

Wise, M. E., D. V. Armstrong, J. T. Huber, R. Hunter, and F. Wiersma. 1988a. Hormonal alterations in the lactating dairy cow in response to thermal stress. J. Dairy Sci. 71:2480-2485.

Wise, M. E., R. E. Rodriguez, D. V. Armstrong, J. T. Huber, F Wiersma, and R. Hunter. 1988b. Fertility and hormonal responses to temporary relief of heat stress in lactating dairy cows. Theriogenology 29:1027-1035. 